\title{
Assessment of Packaged Foods and Beverages Carrying Nutrition Marketing against Canada's Food Guide Recommendations
}

\author{
Beatriz Franco-Arellano ${ }^{1}$, Min Ah Kim ${ }^{1,2}$, Stefanie Vandevijvere ${ }^{3}$, Jodi T. Bernstein ${ }^{1} \mathbb{D}$, \\ Marie-Ėve Labonté ${ }^{1,4}{ }^{\mathbb{D}}$, Christine Mulligan ${ }^{1}$ and Mary R. L'Abbé ${ }^{1, *}$ \\ 1 Department of Nutritional Sciences, Faculty of Medicine, University of Toronto, \\ Toronto, ON M5S 1A8, Canada; beatriz.francoarellano@mail.utoronto.ca (B.F.-A.); \\ minahk.kim@mail.utoronto.ca (M.A.K.); jodi.bernstein@mail.utoronto.ca (J.T.B.); \\ Marie-Eve.Labonte@fsaa.ulaval.ca (M.-Ė.L.); christine.mulligan@mail.utoronto.ca (C.M.) \\ 2 Dalla Lana School of Public Health, University of Toronto, Toronto, ON M5S 1A1, Canada \\ 3 Department of Epidemiology and Biostatistics, School of Population Health, University of Auckland, \\ Auckland 1010, New Zealand; s.vandevijvere@auckland.ac.nz \\ 4 School of Nutrition \& Institute of Nutrition and Functional Foods, Laval University, \\ Québec, QC G1V 0A6, Canada \\ * Correspondence: mary.labbe@utoronto.ca; Tel.: +1-416-978-7235
}

Received: 24 January 2019; Accepted: 13 February 2019; Published: 15 February 2019

check for updates

\begin{abstract}
Canadians' food purchases consist largely of packaged processed and ultra-processed products, which typically fall outside the "core" foods recommended by Canada's Food Guide (CFG). Almost half of packaged products in Canada carry nutrition marketing (i.e., nutrient content and health claims). This study assessed whether packaged foods carrying nutrition marketing align with recommendations outlined in the 2007 CFG. Label data $(n=9376)$ were extracted from the 2013 Food Label Information Program (FLIP). Label components (including nutrition marketing) were classified using the International Network for Food and Obesity/NCDs Research, Monitoring and Action Support (INFORMAS) labelling taxonomy. The Health Canada Surveillance Tool (HCST) was used to assess the alignment of products to CFG. Each food or beverage was classified into one of five groups (i.e., Tier 1, Tier 2, Tier 3, Tier 4, "Others"). Products in Tier 1, 2 or water were considered "in line with CFG". Most products in the analyzed sample were classified as Tier $2(35 \%)$ and Tier $3(27 \%)$. Although foods with nutrition marketing were significantly more likely to align to CFG recommendations $(p<0.001)$, many products not "in line with CFG" still carried nutrition marketing. This study provides important baseline data that could be used upon the implementation of the new CFG.
\end{abstract}

Keywords: dietary guidelines; Canada's food guide; INFORMAS; health Canada surveillance tool; nutrition marketing; nutrient and health claims; food supply

\section{Introduction}

The increase in obesity and diet-related non-communicable diseases (NCDs) is a concern and action needs to be taken to reduce this global health burden [1]. More worrisome is the fact that diet-related mortality is not only increasing but appearing earlier in life, affecting both developed and developing countries [1-3]. Therefore, adherence to a healthy diet remains critical to prevent obesity and NCDs, as well as all forms of malnutrition [4].

Dietary guidelines aim to promote healthy diets and lifestyles through country-specific and science-based agricultural, food, health and nutrition recommendations [5]. Many countries have 
issued and/or updated national dietary guidelines, and reviews of these have been published worldwide [6,7]. Adherence to national dietary guidelines has been found to be associated with reductions in diet-related risk factors and obesity [8-13]. Since first released in 1942, Canada's Food Guide (CFG) has communicated dietary guidance to Canadians [14]. However, the diets of Canadians have been found to be only partially aligned with CFG's recommendations [15]. Public consultations launched in 2016 and 2017 to revise CFG (issued in 2007 and upgraded in 2019) have highlighted the need to create greater awareness of the nutritional quality of foods through strategies such as providing simple and accurate nutrition labelling to consumers, developing schemes that facilitate decision-making when purchasing foods, assessing the impact of ultra-processed foods on health, and limiting intakes of processed or prepared foods and beverages with high sodium, sugars or saturated fat content, among others [16-18]. As such, dietary guidelines can be used as policy tools to influence not only diet recommendations (e.g., daily fruit and vegetable intake), but also the food environment (e.g., school food programs, stimulating product reformulation by industry) $[5,6]$.

The food environment, defined as "the collective physical, economic, policy and sociocultural surroundings, opportunities and conditions that influence people's food and beverage choices and nutritional status" [19], has been found to play a critical role in driving diets [20]. For instance, an unhealthy food environment is known to induce unhealthy diets (i.e., diets characterized by low consumption of fruit and vegetables, and high consumption of foods with high contents of sodium, sugars, saturated and trans fats [1]), and energy overconsumption by increasing the availability and affordability of processed and ultra-processed foods, which are foods commonly high in added fat, sugars and/or sodium [21,22]. In Canada, $>60 \%$ of dietary energy is derived from ultra-processed foods [23], most of which fall outside the "core" foods recommended by CFG [24]. Processed and ultra-processed foods also tend to carry a considerable number of nutrient content and health claims (hereafter referred to as "nutrition marketing") [25-29], which is a significant driver of consumers' purchasing choice $[30,31]$. Canadians consume the majority of their calories from foods prepared at home; however, meals have been found to exceed the recommendations for saturated fat, sugars and sodium [32], which could reflect the rise in use of packaged foods and ready-to-eat meals at home [32-34]. Such changes in consumer behavior could be derived from the trade-offs between convenience, time, availability and the nutritional quality of foods consumers often face when making foods choices [34].

It has been suggested that attitudes towards healthy eating could be improved if the food environment (including the food supply) facilitated healthier food choices $[1,3,35]$. Hence, there has been a particular focus on the implementation of policies and programs that influence holistic changes to the food environment, such as strengthening national dietary guidelines along with other targeted policies, like regulating the marketing of foods with low-nutritional quality [5]. These cost-effective policies and programs can be useful for reducing obesity and other NCDs risk factors [36-44]. The CFG (upgraded in 2019) advises consumers to be aware of the use of nutrition marketing on food labels; however, little data assessing the association of foods with nutrition marketing to its predecessor is available. Therefore, considering that Canadians' food purchases come largely from packaged foods, nutrition marketing is highly prevalent on these foods, and being aware of marketing practices is one key recommendation of the CFG's newest version, the primary objective of this study was to assess whether packaged foods carrying nutrition marketing are in line with the 2007 Canada's Food Guide recommendations, as baseline data upon the implementation of the revamped guideline. A secondary objective was to determine the use of other label components (e.g., supplementary nutrition information) that could also provide consumers with other tools to make decisions.

\section{Materials and Methods}

Food and beverage products that have been shown to be associated with increased risk of obesity and diet-related NCDs worldwide (e.g., convenience foods or packaged meals, sugar sweetened beverages, refined grains, processed meats), and foods associated with healthier food patterns (e.g., 
high consumption of fruits, vegetables, nuts and legumes) [3,36,45-48] ( $n=9376)$ were included as part of this convenience sample of products selected from the 2013 Food Label Information Program (FLIP) [49]. This sample reflects foods commonly consumed by Canadians (e.g., energy-dense, high-fat, low-fiber foods [47]).

FLIP $2013(n=15,342)$ is a database that contains label information for Canadian packaged foods and non-alcoholic beverages [49]. Briefly, FLIP 2013 data were acquired by examining grocery store shelves and photographing food labels of packaged foods and beverages that were on grocery store shelves from the top four Canadian grocers (Loblaws, Metro, Safeway, and Sobeys), which represented approximately $75 \%$ of the Canadian grocery retail market share [49]. The data collection took place between May and September 2013. Information was collected from all products bearing a mandatory Nutrition Facts table (NFt), including all flavour variations of national brands and private labels, but only one package size of each product was collected. Products were excluded from collection if an NFt was not displayed on the label (e.g., breads baked at the store). Products were also not collected if they were seasonal products (e.g., Easter chocolates, Christmas eggnog), natural health products, alcoholic beverages or baby foods. Data were collected using smartphones and uploaded onto the FLIP website, specially designed to store food label information. Trained staff extracted and verified label information such as nutrition information, list of ingredients, brand, container size, universal product code (UPC) and price [25,49].

\subsection{Classification of Label Components}

Label information was classified using the International Network for Food and Obesity/NCDs Research, Monitoring and Action Support (INFORMAS) food labelling taxonomy [44]. INFORMAS is "a global network of public interest organizations and researchers that aims to monitor and benchmark food environments and support public and private sector actions to reduce NCDs and obesity, and their inequalities" [20]. The INFORMAS taxonomy is an internationally standardized methodology for the collection and comparison of nutrition-related marketing on packaged foods and beverages [44]. The purpose of using the INFORMAS taxonomy was two-fold: to allow objective comparison with similar studies that have investigated nutrition marketing in the food supply worldwide [27,29,50-53], and to minimize bias towards identification of other label components that are not currently mandated in Canada (e.g., supplementary nutrition information and quantitative ingredient declaration). This taxonomy divides nutrition-related labelling on food packages into the following two components: (1) nutrition information and, (2) nutrition and health claims [48].

\subsubsection{Nutrition Information}

- List of ingredients: presence/absence of a list of ingredients and other aspects of the list of ingredients (e.g., whether a quantitative ingredient declaration [QUID] was made). The \% symbol was searched for in the list of ingredients to verify products with QUID. Products were not considered as displaying QUID if the quantification referred to: \% additives (e.g., "contains $2 \%$ or less of each of the following: sodium aluminum phosphate, baking soda, artificial flavors, salt), $\%$ origin (e.g., "100\% Canadian milk"), \% organic (e.g., "100\% organic ingredients").

- Nutrient declarations: presence/absence of the Nutrition Facts table.

- Supplementary nutrition information: presence/absence of interpretive nutrition information, such as traffic light labeling (TLL), health star ratings (HSR), or guideline daily amounts (GDA).

\subsubsection{Nutrition and Health Claims (i.e., Nutrition Marketing)}

The INFORMAS taxonomy divides claims into 3 major categories [44] which are:

- Nutrition claims: including nutrient content claims, nutrient comparative claims and health-related ingredient claims). 
- Health claims: including general health claims, nutrient and other function claims, and reduction of disease risk claims). Logos or heart-shaped symbols (such as the ones used by national heart foundations like the British Heart Foundation or the Australia/New Zealand Heart Foundation Tick) were considered as reduction of disease risk claims because they seem to imply a relationship between the consumption or a product and cardiovascular disease risk [44]. In Canada, a similar symbol was used at the time of data collection (the Heart and Stroke Foundation [HSF] logo) and therefore was classified as such for the propose of this study; however, it is important to note that the logo did not comply with the Canadian regulations for disease risk reduction claims and therefore it could instead be considered as an unregulated general health claim. The HSF logo was discontinued in 2014 (a year after data was collected).

- Other claims: included other health-related claims (e.g., "gluten-free" claims) and environment-related claims (e.g., "organic"), but they were not analyzed in the present study as they are not considered "nutrients".

Examples of nutrition and health claims as per the INFORMAS taxonomy are shown in Supplementary Table S1. Label components were identified and extracted by two researchers (B.F.-A., M.A.K.) by reviewing photographs of each individual food label included in the current study. An Excel database was created in which label components were coded for each food or beverage and which was later validated for accuracy. If uncertainties about classification arose, such doubts were discussed among researchers and a final classification was agreed upon.

\subsection{Food Category Classification}

The Global Food Monitoring Group (GFMG) system was used to classify the selected sample of foods into food categories, as established by the INFORMAS labelling protocol (see Supplementary Table S2 for details of the GFMG food categories) [48,54]. Food products were classified into the following food categories: beverages; bread and bakery products; cereal and grain products; confectionery; desserts and ice cream and edible ices; eggs; fruits and vegetables (including nuts and legumes); snack foods; processed fish; meat and meat alternatives; sauces, dressings and condiments; and sugar, honey and related products.

\subsection{Classification of Products According to Health Canada Surveillance Tool Nutrient Profiling System}

The Health Canada Surveillance Tool (HCST) is the first government-based Canadian nutrient profiling system (NP), and was developed to assess Canadians' adherence to the 2007 Canada's Food Guide (CFG), in terms of the amount and the nutritional quality of food choices [55]. The HSCT has been validated against the World Health Organization's (WHO) recommendations of the nutrients/food components that characterize "healthy" and "unhealthy" diets (i.e., content validity), as well as its ability to characterize the nutritional quality of foods in the Canadian context compared to other NP models (i.e., construct/convergent validity) [1,56]. The HCST classifies foods within each of the CFG's food groups (i.e., Vegetables and Fruits, Grain products, Milk and alternatives, Meat and alternatives) into four tiers, based on their fats, sugars and sodium content (Table 1). A fifth group, "Others", which consists of foods and beverages that fall outside of the four food groups (i.e., high calorie beverages ( $\geq 40 \mathrm{kcal} / 100 \mathrm{~g}$ ), low calorie beverages ( $<40 \mathrm{kcal} / 100 \mathrm{~g})$, high fat and/or sugar foods, meal replacements, saturated and/or trans fats and oils, supplements, ingredients/seasonings, water and unsaturated fats and oils) was also included. Each food or beverage in FLIP 2013 was classified into one of those five groups (i.e., Tier 1, Tier 2, Tier 3, Tier 4 and "Others"). Algorithms were developed by the research team (M.-E.L, B.F.-A., J.T.B., C.M.) to systematically classify foods and beverages in FLIP 2013 using the HCST Tier system. Foods were considered to be "in line with CFG" if they had been classified as Tier 1, Tier 2 and "other foods and beverages recommended in CFG", such as water and unsaturated fats and oils. Unsaturated fats and oils were not found in this sample, otherwise, such products would also have been considered to be "in line with CFG". The rest of the foods and beverages were considered to be "not in line with CFG" (Table 1). 
Table 1. Health Canada Surveillance Tool Tier Thresholds ${ }^{1}$.

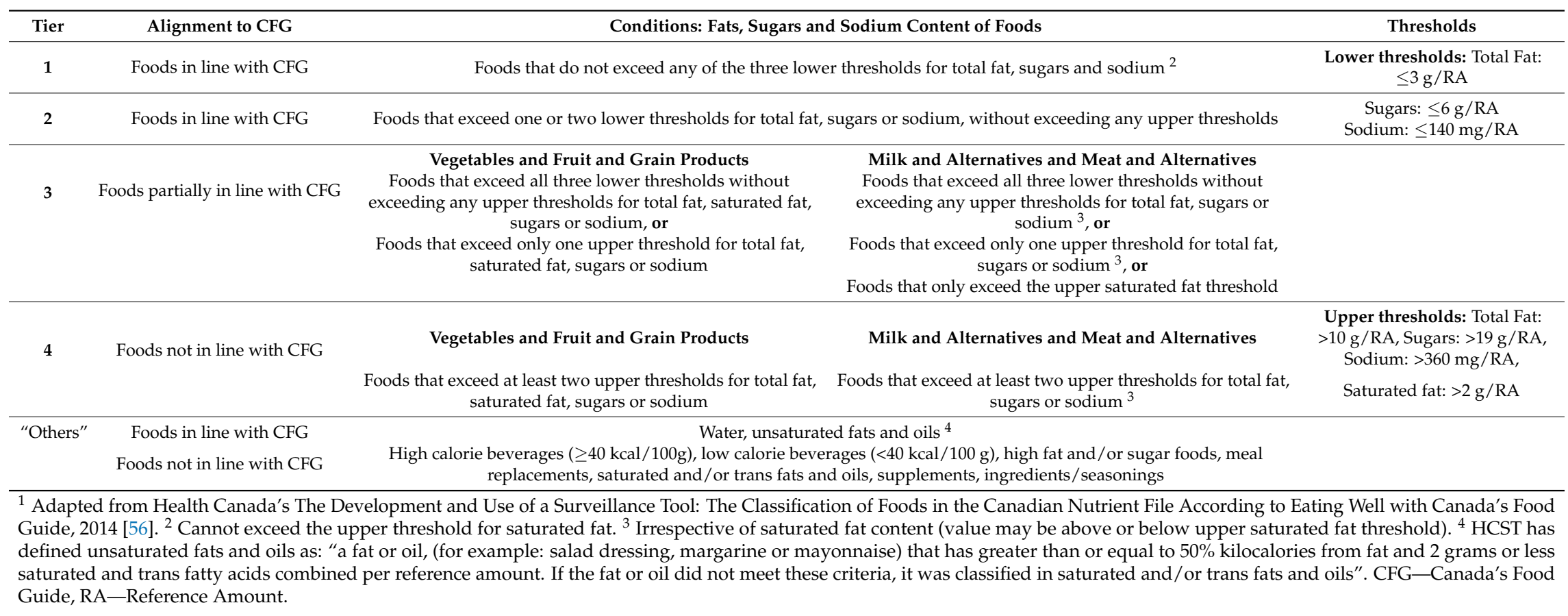




\subsection{Data Analysis}

The proportion (\%) of different label components in this sample of Canadian foods was calculated overall and by food category. The proportion (\%) of products in each tier (i.e., Tier 1, 2, 3, 4, and "Others") was calculated overall, by food category and by the types of nutrition and health claims. The proportion (\%) of foods and beverages that were considered "in line with CFG" (i.e., Tiers 1 and 2 , and "other foods and beverages recommended in CFG", such as water and unsaturated fats and oils) and those considered "not in line with CFG" was also calculated for products with and without each type of claim. Binomial logistic regression models (one per type of claim) were used to examine the association between the presence and nature of nutrition marketing (i.e., type of claim) and the adherence of products bearing such claims to the CFG (i.e., "in line with CFG") compared to those "in line with $C F G$ " but without claims. Analyses were conducted using the statistical software package R. A $p$ value of less than 0.05 was deemed statistically significant.

\section{Results}

\subsection{Label Components}

Table 2 provides an overview of the different label components displayed on Canadian foods, as determined by the INFORMAS food labelling taxonomy. Since the Nutrition Facts table and Ingredients List are mandatory components in mostly all foods in Canada, and the presence of those elements was required for products to be collected in FLIP, all food labels in this sample displayed such information. However, quantitative ingredient declarations characterizing the amount of ingredients (e.g., percentage of fruit in a canned fruit product), was available for only $2.6 \%$ of products $(n=$ 241/9379), and mostly in the following food categories: cereal and grain products $(n=71 / 241)$, beverages $(n=54 / 241)$, confectionery $(n=33 / 241)$ and bakery products $(n=27 / 241)$. Supplementary nutrition information was also only used in a small proportion of products $(1.2 \%)$, of which only GDA symbols were identified in the analyzed food products; none of the products carried traffic light or health star rating symbols. Ninety-three percent (93\%) of the total products with GDA labels were found in the following categories: bakery products $(n=50 / 114)$, cereal and related products $(n=$ 41/114) and confectionary ( $n=15 / 114)$.

More than half of the foods and beverages in this sample (52\%) carried some type of nutrition marketing, according to the INFORMAS Taxonomy (Table 2). Nutrient content claims were the most prevalent type of claims used on labels $(46 \%)$, followed by health-related ingredient claims $(17 \%)$. Such claims were primarily related to the presence of whole grains, fruits, vegetables or other plant-based ingredients (data not shown). Nutrient or other function claims were the least frequent, being displayed on only $0.8 \%$ of foods. Health claims were present on $7 \%$ of labels, and mostly consisted of reduction of disease risk claims and general health claims $(4.1 \%$ and $2.7 \%$, respectively).

\subsection{Proportion of Foods and Beverages in Each Tier}

Overall, most food products were classified under Tier 2 and Tier 3 (Table 2). Foods classified under "Others" were mostly products "not in line with CFG" $(98 \%, n=1610 / 1613)$.

When the distribution of foods carrying nutrition marketing $(n=4897)$ within each tier was analyzed by the type of claim (Figure 1), it was found overall that foods carrying claims were primarily classified in Tier 1 and Tier 2 (59.1\%), although over a quarter of these foods were also classified in Tier 3 and Tier 4 (23.3\% and 5.4\%, respectively). As expected, the distribution of foods into the Tiers varied across different types of claims. For example, products carrying health claims $(>80 \%)$ were most likely classified as Tier 1 and Tier 2, although the overall prevalence of such products within the sample was limited $(7.3 \%)$. 
Table 2. Proportions of label components and HCST Tier classification on a sample of Canadian packaged foods $(n=9376)^{1,2,3}$

\begin{tabular}{|c|c|c|c|c|c|c|c|c|c|c|c|c|c|c|}
\hline & \multicolumn{2}{|c|}{ Bakery $(n=2083)$} & \multicolumn{2}{|c|}{ Beverages $(n=1124)$} & \multicolumn{2}{|c|}{ Cereals $(n=1218)$} & \multicolumn{2}{|c|}{ Ice Creams \& Desserts $(n=820)$} & \multicolumn{2}{|c|}{ Confectionary $(n=437)$} & \multicolumn{2}{|c|}{ Sugar \& Honey $(n=193)$} & \multicolumn{2}{|c|}{ Snacks $(n=558)$} \\
\hline & $n$ & $\%$ & $n$ & $\%$ & $n$ & $\%$ & $n$ & $\%$ & $n$ & $\%$ & $n$ & $\%$ & $n$ & $\%$ \\
\hline Label Components & & & & & & & & & & & & & & \\
\hline $\begin{array}{l}\text { List of ingredients } \\
\text { Foods }\end{array}$ & ${ }_{27}^{2083}$ & $100 \%$ & ${ }_{54}^{1124}$ & $100 \%$ & ${ }_{71}^{218}$ & $100 \%$ & ${ }^{820}$ & $100 \%$ & 437 & $100 \%$ & 193 & $100 \%$ & 558 & $100 \%$ \\
\hline $\begin{array}{l}\text { Foods with QUID } \\
\text { Nutrient declarations (NFt) }\end{array}$ & 2083 & $100 \%$ & $\begin{array}{c}54 \\
1124\end{array}$ & $\begin{array}{l}.8 .8 \% \\
100 \%\end{array}$ & 1218 & $\begin{array}{l}3.8 \% \\
100 \%\end{array}$ & $\begin{array}{l}12 \\
820\end{array}$ & $100 \%$ & $\begin{array}{l}33 \\
437\end{array}$ & $\begin{array}{l}8 \% \\
100 \%\end{array}$ & 193 & $\begin{array}{l}3.2 \% \% \\
100 \%\end{array}$ & $\begin{array}{l}18 \\
558\end{array}$ & $\begin{array}{l}3.2 \% \\
100 \%\end{array}$ \\
\hline Supplementary Nutrition Information & 50 & $2.4 \%$ & 0 & $0.0 \%$ & 41 & $3.4 \%$ & 0 & $0.0 \%$ & $\begin{array}{l}43 \\
15\end{array}$ & $3 \%$ & $\begin{array}{c}193 \\
0\end{array}$ & 0 & $\begin{array}{c}538 \\
6\end{array}$ & $\begin{array}{l}100 \% \\
1.1 \%\end{array}$ \\
\hline $\begin{array}{l}\text { Any nutrition or health claim } \\
\text { Yes }\end{array}$ & 1153 & $55.4 \%$ & 790 & $70.3 \%$ & 675 & $55.4 \%$ & 426 & $52.0 \%$ & 150 & $34 \%$ & 43 & $22.3 \%$ & 405 & $72.6 \%$ \\
\hline Nutrition claims & 1146 & $55.0 \%$ & 790 & $70.3 \%$ & 672 & $55.2 \%$ & 426 & $52.0 \%$ & 146 & $33 \%$ & 43 & $22.3 \%$ & 405 & $72.6 \%$ \\
\hline Nutrient content claims & 970 & $46.6 \%$ & 736 & $65.5 \%$ & 614 & $50.4 \%$ & 351 & $42.8 \%$ & 79 & $18 \%$ & 28 & $14.5 \%$ & 378 & $67.7 \%$ \\
\hline Nutrient comparative claims & 41 & $2.0 \%$ & 37 & $3.3 \%$ & 11 & $0.9 \%$ & 58 & $7.1 \%$ & 3 & $1 \%$ & 15 & $7.8 \%$ & 51 & $9.1 \%$ \\
\hline $\begin{array}{l}\text { Health-related ingredient claims } \\
\text { Health chaims }\end{array}$ & 518 & $\begin{array}{l}24.9 \% \\
103 \%\end{array}$ & 329 & $29.3 \%$ & 347 & $28.5 \%$ & 105 & $12.8 \%$ & 75 & $17 \%$ & 4 & $2.1 \%$ & 112 & $20.1 \%$ \\
\hline $\begin{array}{l}\text { Health claims } \\
\text { General health claims }\end{array}$ & $\begin{array}{l}215 \\
149\end{array}$ & $10.3 \%$ & ${ }_{53}^{112}$ & $10.0 \%$ & 155 & $12.7 \%$ & 28 & $3.4 \%$ & $\begin{array}{l}5 \\
5\end{array}$ & $1 \%$ & 1 & $0.5 \%$ & 21 & $3.8 \%$ \\
\hline $\begin{array}{l}\text { General health claims } \\
\text { Nutrient or other function claims }\end{array}$ & $\begin{array}{l}149 \\
17\end{array}$ & $\begin{array}{l}7.2 \% \\
0.8 \%\end{array}$ & $\begin{array}{c}53 \\
0\end{array}$ & $\begin{array}{l}4.7 \% \\
0.0 \%\end{array}$ & $\begin{array}{l}23 \\
10\end{array}$ & $\begin{array}{l}1.9 \% \\
0.8 \%\end{array}$ & $\begin{array}{l}11 \\
15\end{array}$ & $\begin{array}{l}1.3 \% \\
1.8 \%\end{array}$ & $\begin{array}{l}5 \\
0\end{array}$ & $1 \%$ & $\begin{array}{l}0 \\
1\end{array}$ & $\begin{array}{l}0.0 \% \\
0.5 \%\end{array}$ & ${ }_{0}^{2}$ & $\begin{array}{l}0.4 \% \\
0.0 \%\end{array}$ \\
\hline $\begin{array}{l}\text { Nutrient or other function claims } \\
\text { Reduction of disisease risk claims }\end{array}$ & $\begin{array}{l}17 \\
57\end{array}$ & $\begin{array}{l}0.8 \% \\
2.7 \%\end{array}$ & $\begin{array}{c}0 \\
72\end{array}$ & $\begin{array}{l}0.0 \% \\
6.4 \%\end{array}$ & $\begin{array}{l}10 \\
127\end{array}$ & $\begin{array}{l}0.8 \% \\
10.4 \%\end{array}$ & $\begin{array}{c}15 \\
2\end{array}$ & $\begin{array}{l}1.8 \% \\
0.2 \%\end{array}$ & $\begin{array}{l}0 \\
0\end{array}$ & $\begin{array}{l}0 \% \\
0 \%\end{array}$ & $\begin{array}{l}1 \\
0\end{array}$ & $\begin{array}{l}0.5 \% \\
0.0 \%\end{array}$ & $\begin{array}{c}0 \\
19\end{array}$ & $\begin{array}{l}0.0 \% \\
3.4 \%\end{array}$ \\
\hline No & 930 & $44.6 \%$ & 334 & $29.7 \%$ & 543 & $\begin{array}{l}44.6 \% \\
44.6 \%\end{array}$ & 394 & $48.0 \%$ & 287 & $66 \%$ & 150 & $77.7 \%$ & 153 & $\begin{array}{l}2.7 \% \text {. } \\
27.4 \%\end{array}$ \\
\hline $\begin{array}{l}\text { HCST Tier Classification } \\
\text { Tier } 1 \text { - In line w/CFG }\end{array}$ & 216 & $10.4 \%$ & 40 & $3.6 \%$ & 454 & $37.3 \%$ & 33 & $4.0 \%$ & & & & & 7 & $13 \%$ \\
\hline Tier 2 - In line w/CFG & 1103 & $53.0 \%$ & 548 & $48.8 \%$ & 583 & $47.9 \%$ & 213 & $26.0 \%$ & & & & & 113 & $20.3 \%$ \\
\hline Tier 3 - Partially in line w/CFG & 520 & $25.0 \%$ & 54 & $4.8 \%$ & 73 & $6.0 \%$ & 445 & $54.3 \%$ & & & & & 308 & $55.2 \%$ \\
\hline \multirow{4}{*}{ Others } & 244 & $11.7 \%$ & & & 18 & $1.5 \%$ & 129 & $15.7 \%$ & & & & & 130 & $23.3 \%$ \\
\hline & & & 482 & $42.9 \%$ & 90 & $7.4 \%$ & & & 437 & $100 \%$ & 193 & $100 \%$ & - & - \\
\hline & \multicolumn{2}{|c|}{ Processed fish $(n=440)$} & \multicolumn{2}{|c|}{ Meat and Meat Alt. $(n=908)$} & \multicolumn{2}{|c|}{ Sauces \& spreads $(n=50)$} & \multicolumn{2}{|c|}{ FVNL $(n=1489)$} & \multicolumn{2}{|c|}{ Eggs $(n=56)$} & \multicolumn{2}{|c|}{ Total Products $(n=9376)$} & & \\
\hline & $n$ & $\%$ & $n$ & $\%$ & $n$ & $\%$ & $n$ & $\%$ & $n$ & $\%$ & $n$ & $\%$ & & \\
\hline Label Components & & & & & & & & & & & & & & \\
\hline List of ingredients & 440 & $100 \%$ & 908 & $100 \%$ & 50 & $100 \%$ & 1489 & $100 \%$ & 56 & $100 \%$ & 9376 & $100 \%$ & & \\
\hline Foods with QUID & 4 & $0.9 \%$ & 1 & $0.1 \%$ & 2 & $4.0 \%$ & 9 & $0.6 \%$ & 0 & $0.0 \%$ & 241 & $2.6 \%$ & & \\
\hline Nutrient declarations $(\mathrm{NFt})$ & 440 & $100 \%$ & 908 & $100 \%$ & 50 & $100 \%$ & 1489 & $100 \%$ & 56 & $100 \%$ & 9376 & $100 \%$ & & \\
\hline $\begin{array}{l}\text { Supplementary Nutrition Information } \\
\text { Ann nutrition or health claim }{ }^{3}\end{array}$ & 0 & $0.0 \%$ & 2 & $0.2 \%$ & 0 & $0.0 \%$ & 0 & $0.0 \%$ & 0 & $0.0 \%$ & 114 & $1.2 \%$ & & \\
\hline $\begin{array}{l}\text { Any nutrtition or nealth claim } \\
\text { Yes }\end{array}$ & 217 & $49.3 \%$ & 339 & $37.3 \%$ & 12 & $24.0 \%$ & 657 & $44.1 \%$ & 30 & $53.6 \%$ & 4897 & $52.2 \%$ & & \\
\hline Nutrition claims & 217 & $49.3 \%$ & 339 & $37.3 \%$ & 12 & $24.0 \%$ & 654 & $43.9 \%$ & 27 & $48.2 \%$ & 4875 & $52.0 \%$ & & \\
\hline Nutrient content claims & 208 & $47.3 \%$ & 291 & $32.0 \%$ & 5 & $10.0 \%$ & 582 & $39.1 \%$ & 27 & $48.2 \%$ & 4269 & $45.5 \%$ & & \\
\hline Nutrient comparative claims & 1 & $0.2 \%$ & 66 & $7.3 \%$ & 0 & $0.0 \%$ & 52 & $3.5 \%$ & 0 & $0.0 \%$ & 335 & $3.6 \%$ & & \\
\hline $\begin{array}{l}\text { Health-related ingredient claims } \\
\text { Helth chaims }\end{array}$ & 8 & $1.8 \%$ & 7 & $0.8 \%$ & 7 & $14.0 \%$ & 113 & $7.6 \%$ & 0 & $0.0 \%$ & 1625 & $17.3 \%$ & & \\
\hline $\begin{array}{l}\text { Health claims } \\
\text { Genernthealth claims }\end{array}$ & 21 & $4.8 \%$ & 12 & $1.3 \%$ & 0 & $0.0 \%$ & 93 & $6.2 \%$ & 23 & $41.1 \%$ & 686 & $7.3 \%$ & & \\
\hline $\begin{array}{l}\text { General health claims } \\
\text { Nutrient or other function claims }\end{array}$ & ${ }_{16}^{1}$ & $0.2 \%$ & $\begin{array}{l}2 \\
5\end{array}$ & $0.2 \%$ & $\begin{array}{l}0 \\
0\end{array}$ & $\begin{array}{l}0.0 \% \\
0.0 \%\end{array}$ & $\begin{array}{l}8 \\
8\end{array}$ & $\begin{array}{l}0.5 \% \\
0.5 \%\end{array}$ & ${ }_{2}^{0}$ & $\begin{array}{l}0.0 \% \\
3.6 \%\end{array}$ & $\begin{array}{l}254 \\
74\end{array}$ & $\begin{array}{l}2.7 \% \\
0.8 \%\end{array}$ & & \\
\hline $\begin{array}{l}\text { Nutrent or other function claims } \\
\text { Reduction of disease risk claims }{ }^{4}\end{array}$ & $\begin{array}{c}16 \\
5\end{array}$ & $\begin{array}{l}3.6 \% \\
1.1 \%\end{array}$ & $\begin{array}{l}5 \\
5\end{array}$ & $\begin{array}{l}0.6 \% \\
0.6 \%\end{array}$ & $\begin{array}{l}0 \\
0\end{array}$ & $\begin{array}{l}0.0 \% \\
0.0 \%\end{array}$ & $\begin{array}{c}8 \\
77\end{array}$ & $\begin{array}{l}0.5 \% \\
5.2 \%\end{array}$ & 22 & $\begin{array}{l}3.6 \% \\
39.3 \%\end{array}$ & $\begin{array}{l}74 \\
386\end{array}$ & $\begin{array}{l}0.8 \% \\
4.1 \%\end{array}$ & & \\
\hline No & 223 & $\begin{array}{l}1.110 \\
50.7 \%\end{array}$ & 569 & $\begin{array}{l}62.7 \% \\
62.7 \%\end{array}$ & 38 & $\begin{array}{l}0.06 \% \\
76.0 \%\end{array}$ & 832 & $55.9 \%$ & 26 & $46.4 \%$ & 4479 & $\begin{array}{l}4.15 \% \\
47.8 \%\end{array}$ & & \\
\hline $\begin{array}{l}\text { HCST Tier Classification }{ }^{5} \\
\text { Tier } 1 \text { - In line w/CFG }\end{array}$ & 50 & & 2 & $0.2 \%$ & & & 143 & $96 \%$ & & & 945 & $101 \%$ & & \\
\hline Tier 2 - In line w/CFG & 174 & $39.5 \%$ & 133 & $14.6 \%$ & & & 405 & $27.2 \%$ & 11 & $19.6 \%$ & 3283 & $35.0 \%$ & & \\
\hline Tier 3 - Partially in line w/CFG & 141 & $32.0 \%$ & 453 & $49.9 \%$ & & & 524 & $35.2 \%$ & 45 & $80.4 \%$ & 2563 & $27.3 \%$ & & \\
\hline Tier 4 - Not in line w/CFG & 75 & $17.0 \%$ & 320 & $35.2 \%$ & & & 56 & $3.8 \%$ & & & 972 & $10.4 \%$ & & \\
\hline Others & & & & & 50 & $100 \%$ & 361 & $24.2 \%$ & & & 1613 & $17.2 \%$ & & \\
\hline
\end{tabular}

${ }^{1}$ Label components were classified using the INFORMAS step-wise approach proposed by Rayner and colleagues (Adapted from: Rayner, M., et.al., Obes Rev, 2013. 14 Suppl 1: pp. 70-81) [44]. ${ }^{2}$ The Health Canada Surveillance Tool (HCST) is a nutrient profiling system developed to assess Canadians' adherence to Canada's Food Guide in terms of amount and the quality of food choices [55]. ${ }^{3}$ A label can include multiple classification of nutrition and health claims therefore total can be $>100 \% .{ }^{4}$ Logos used by national heart foundations such as the British Heart Foundation or the Australia/New Zealand Heart Foundation Tick were considered as reduction of disease risk claims. In Canada, a similar symbol was used at the time of data collection (the Heart and Stroke Foundation logo) and was therefore classified as such for the purpose of this study; however, the logo did not comply with the Canadian regulations for disease risk reduction claims and it could instead be considered as an unregulated general health claim. The Heart and Stroke Foundation logo was discontinued in 2014 . $^{5}$ Foods within each of CFG's food groups were classified into four tiers, based on their fats, sugars and sodium content, or "Others") as indicated in Table 1. HCST-Health Canada Surveillance Tool; QUID—Quantitative ingredient declaration; NFt—Nutrition Facts table; CFG—Canada's Food Guide; FVNL—Fruit, Vegetables, Nuts, Legumes; Alt—Alternatives. 


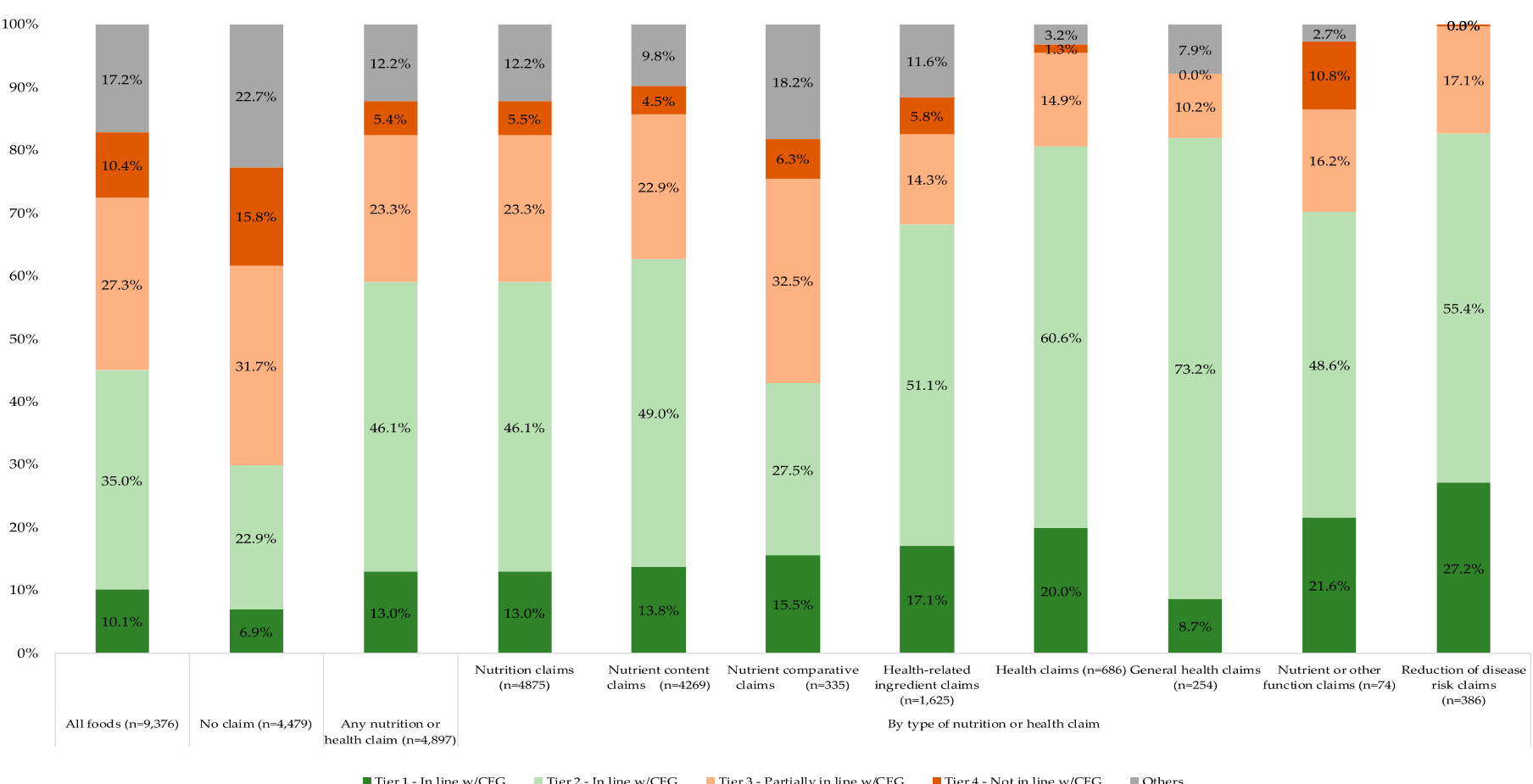

Figure 1. Proportion of foods and beverages in each tier by type of nutrition marketing $1,2,3,4,5 .{ }^{1}$ Label components were classified using the INFORMAS step-wise approach proposed by Rayner and colleagues (adapted from: Rayner, M., et.al., Obes Rev, 2013. 14 Suppl 1: pp. 70-81) [44]. ${ }^{2}$ The Health Canada Surveillance Tool (HCST) is a nutrient profiling system developed to assess Canadians' adherence to Canada's Food Guide in terms of amount and the quality of food choices [55]. ${ }^{3}$ A label can include multiple classifications of nutrition and health claims therefore the total can be $>100 \% .{ }^{4}$ Logos used by national heart foundations such as the British Heart Foundation or the Australia/New Zealand Heart Foundation Tick were considered as reduction of disease risk claims. In Canada, a similar symbol was used at the time of data collection (the Heart and Stroke Foundation logo) and was therefore classified as such for the purpose of this study; however, the logo did not comply with the Canadian regulations for disease risk reduction claims and it could instead be considered as an unregulated general health claim. The Heart and Stroke Foundation logo was discontinued in 2014. ${ }^{5}$ Foods within each of CFG's food groups were classified into four tiers, based on their fats, sugars and sodium content, or "Others") as indicated in Table 1. HCST—Health Canada Surveillance Tool; QUID—Quantitative ingredient declaration; NFt—Nutrition Facts table; CFG—Canada's Food Guide; Alt-Alternatives. 
Foods carrying nutrient comparative claims were primarily found in Tier 3, Tier 4 or "Others" (57\%). Table 3 shows the logistic regression coefficients (unadjusted and adjusted model for food category) used to estimate the association of a product carrying each type of claim to being "in line with CFG" compared to those without claims that are also "in line with CFG". Overall, in unadjusted models, the presence of almost all types of claims (except for nutrient comparative claims) significantly increased the likelihood that a product would be "in line with CFG", as evidenced by their positive and significant coefficients (Table 3).

Table 3. Associations of foods carrying different types of claims to CFG recommendations $(n=9376)^{1,2}$.

\begin{tabular}{|c|c|c|c|c|c|c|c|c|c|}
\hline & \multirow{2}{*}{$\begin{array}{c}\text { Total } \\
n\end{array}$} & \multicolumn{2}{|c|}{ In Line with CFG } & \multicolumn{3}{|c|}{ Unadjusted Model } & \multicolumn{3}{|c|}{ Adjusted Model } \\
\hline & & $n$ & $\%$ & $\beta$-Coefficients & $\mathrm{SE}$ & & $\beta$-Coefficients & SE & \\
\hline \multicolumn{10}{|c|}{ Any nutrition or health claim } \\
\hline Absent+ & 4479 & 1338 & $29.9 \%$ & & & & & & \\
\hline Present & 4897 & 2893 & $59.1 \%$ & 1.22 & 0.044 & $* * *$ & 1.36 & 0.052 & $* * *$ \\
\hline \multicolumn{10}{|c|}{ Nutrition claims } \\
\hline Absent+ & 4501 & 1351 & $30.0 \%$ & & & & & & \\
\hline Present & 4875 & 2880 & $59.1 \%$ & 1.21 & 0.044 & $* * *$ & 1.35 & 0.052 & $* * *$ \\
\hline \multicolumn{10}{|c|}{ Nutrient content claims } \\
\hline Absent+ & 5107 & 1551 & $30.4 \%$ & & & & & & \\
\hline Present & 4269 & 2680 & $62.8 \%$ & 1.35 & 0.044 & $* * *$ & 1.50 & 0.053 & $* * *$ \\
\hline \multicolumn{10}{|c|}{ Nutrient comparative claims } \\
\hline Absent+ & 9041 & 4087 & $45.2 \%$ & & & & & & \\
\hline Present & 335 & 144 & $43.0 \%$ & -0.09 & 0.112 & ns & 0.52 & 0.127 & $* * *$ \\
\hline \multicolumn{10}{|c|}{ Health-related ingredient claims } \\
\hline Absent+ & 7751 & 3122 & $40.3 \%$ & & & & & & \\
\hline Present & 1625 & 1109 & $68.2 \%$ & 1.16 & 0.058 & $* * *$ & 0.91 & 0.068 & $* * *$ \\
\hline \multicolumn{10}{|c|}{ Health claims } \\
\hline Absent+ & 8690 & 3678 & $42.3 \%$ & & & & & & \\
\hline Present & 686 & 553 & $80.6 \%$ & 1.73 & 0.099 & $* * *$ & 1.51 & 0.111 & $* * *$ \\
\hline \multicolumn{10}{|c|}{ General health claims } \\
\hline Absent+ & 9122 & 4023 & $44.1 \%$ & & & & & & \\
\hline Present & 254 & 208 & $81.9 \%$ & 1.75 & 0.164 & $* * *$ & 1.36 & 0.178 & $* * *$ \\
\hline \multicolumn{10}{|c|}{ Nutrient or other function claims } \\
\hline Absent+ & 9302 & 4179 & $44.9 \%$ & & & & & & \\
\hline Present & 74 & 52 & $70.3 \%$ & 1.06 & 0.255 & $* * *$ & 1.13 & 0.281 & $* * *$ \\
\hline \multicolumn{10}{|c|}{ Reduction of disease risk claims } \\
\hline Absent+ & 8990 & 3912 & $43.5 \%$ & & & & & & \\
\hline Present & 386 & 319 & $82.6 \%$ & 1.82 & 0.136 & $* * *$ & 1.69 & 0.157 & $* * *$ \\
\hline
\end{tabular}

\footnotetext{
${ }^{1}$ Main effects of binary logistic regression models (unadjusted and adjusted for food category). Foods classified in Tier 1, Tier 2 and water were considered "in line with Canada's Food Guide". ${ }^{2}$ Logos used by national heart foundations such as the British Heart Foundation or the Australia/New Zealand Heart Foundation Tick were considered as reduction of disease risk claims. In Canada, a similar symbol was used at the time of data collection (the Heart and Stroke Foundation logo) and was therefore classified as such for the purpose of this study; however, the logo did not comply with the Canadian regulations for disease risk reduction claims and it could instead be considered as an unregulated general health claim. + Indicates reference category. The significance of the coefficients is indicated by the following codes: ns $p>0.05,{ }^{* * *} p<0.001$. CFG—Canada's Food Guide; SE-Standard Error.
}

For example, foods carrying nutrition claims or health claims are $21 \%$ and $73 \%$ more likely to be "in line with CFG" than products without those claims, respectively.

Nutrient comparative claims showed a negative value (i.e., a product is likely "not in line with CFG" if this claim is featured on the label), but it was not significant $(p=0.42)$. Products with nutrient comparative claims were further analyzed to determine possible reasons for the lack of association and it was found that $56 \%$ of foods with such claims fell within snacks $(n=51 / 335)$, meat and meat alternatives including mostly ham, salami, burgers, bacon $(n=66 / 335)$, ice creams and desserts $(n=58 / 335)$ and sugars and honey $(n=15 / 335)$; food categories highly discouraged in dietary guidelines. Such results are not surprising since, for example, all products within sugars and honey were classified as "Others" and 78\% of snacks were classified as Tier 3 and Tier 4 (Table 2). When the adjusted models were analyzed, all types of nutrition and health claims were found to be significantly more likely to be "in line with CFG". Such analyses suggest that not only the presence, but also the type of claim is associated with food category. 


\section{Discussion}

Packaged foods and beverages, which frequently display nutrition marketing, are commonly purchased by Canadians. This study investigates the alignment of a sample of Canadian packaged foods and beverages carrying nutrition marketing with the 2007 Canada's Food Guide recommendations, using the Health Canada Surveillance Tool to provide baseline data upon the implementation of the new CFG guideline. In addition, this study also examined the use of other label components, such as supplementary nutrition information and QUID, which are currently not mandatory in Canada.

With respect to the alignment of foods and beverages with the CFG's recommendation, most products in this sample were considered Tier 2, Tier 3, and "Others" (predominantly those "not in line with CFG", such as high calorie beverages, high-fat and/or sugar foods, and saturated and/or trans fats and oils [15]). Interestingly, these results mirror the findings from another study that investigated the nutritional quality of diets in Canadian individuals using the HSCT, which found most dietary choices made by Canadians were from Tier 2, Tier 3 as well as "Others not in line with CFG". Our study therefore aligns with previous research that has suggested consuming packaged foods might restrict healthy eating [23,57].

Despite the NFt being reported as the primary source of nutrition information used by Canadians [58], consumers may not be able to easily identify and understand the nutrition information provided on the NFt [59] and therefore may rely on nutrition marketing that mostly appears on the front of packages to make purchasing decisions [60]. Results in the present study revealed that the presence of nutrition marketing increases the association of packaged foods of being aligned with CFG recommendations. This suggests that nutrition marketing may be a good indicator of healthier choices. However, consumers should be aware that many foods with nutrition marketing still fall outside CFG's recommendations. For instance, $23.3 \%$ of foods with nutrition marketing in this study were classified as Tier 3 and $17.6 \%$ of foods with claims were classified into Tier 4 and "Others". Moreover, $32 \%$ of foods with nutrient comparative claims were classified as Tier 3 and likely to be found in snacks, meat and meat alternatives, ice creams and desserts, and sugars and honey food categories. Moreover, since its inception, CFG has been criticized for being "obesogenic" [61,62] due its lack of cautionary advice to consumers about the consequences of consuming excess calories, as well as products from Tier 4 and "Others" (mostly high energy foods and beverages) [14,61]. This is concerning given that almost one-third of products consumed by Canadians come from foods in Tier 4 and "Others", sources not recommended by the CFG [15]. While this study suggests nutrition marketing is associated with better alignment to the CFG, there are still many foods with nutrition marketing that are of poor nutritional quality, and therefore consumers should be cautious when using nutrition marketing for dietary decision making $[63,64]$.

The use of other label elements, such as mandatory supplementary nutrition information (i.e., front-of-pack [FOP] labelling) could strengthen the nutrition information given to consumers and could help them to identify foods that exceed thresholds for nutrients of public health concern such as sodium, sugars and saturated fats [65]. Findings from the current study showed that the presence of supplementary nutrition information in Canada is low $(1.2 \%)$ and was displayed primarily in the form of GDA. GDA have been identified in other research as the least effective system for consumers to differentiate "healthier" from "less healthy" food options [66-68]. Notably, a proposal to regulate the use of supplementary nutrition information in the form of "high in" symbols, a system that has been shown to be more effective $[69,70]$ and identified as a key recommendation during CFG consultations [16], has recently been issued in Canada [65].

Although the prevalence of nutrition marketing on Canadian labels has been previously examined [25], benchmarking to international standards and comparisons to other studies were limited due to jurisdictional differences in nutrition marketing terminology. By coding claims using the standardized approach outlined by INFORMAS [44,48], comparisons are now feasible. This analysis showed that overall food labels in Canada are more heavily marketed (i.e., prevalence of 
nutrition marketing) (52\%) than in New Zealand (39\%) [51], Slovenia (39\%) [29], the UK (32\%) [52], five European countries (26\%) [50], and Thailand (25\%) [53], although Canada showed similar proportions to Australia (56\%) [27]. However, in many of those countries other nutrition regulations are already in place to restrict the use of nutrition marketing on foods with an "unhealthy" nutritional profile; for example, through the use of nutrient profiling models to determine if a food is eligible to carry certain claims [71,72]. If such regulations were implemented in Canada, it may be even more likely that foods with nutrition marketing would align with dietary guidelines, and less likely to be on foods high in nutrients of public health concern.

There are some limitations to this present analysis. First, a convenience sample was used instead of the full 2013 FLIP database. However, this sample included most foods that have been associated with increased risk of diet-related NCDs and "healthier" food patterns. Second, the data was collected five years ago and therefore, some products could have changed labels, could have been reformulated, or even been removed from the market. However, an assessment with respect to the 2007 CFG recommendations is valuable since such guideline was current at the time of data collection. In addition, the nutrient profiling model (i.e., HCST), developed based on the 2007 CFG, has not been updated with the revamp of the 2019 CFG and it is still the most up-to-date government-led nutrient profiling in Canada. It is also unknown whether the HCST will be updated to reflect new recommendations and when such upgrade could occur. Therefore, these results can provide baseline data upon the implementation of the 2019 CFG and be used to assess changes overtime once the new guideline is fully integrated to dietary practices. As such, studies assessing nutrition marketing and their association with new the guideline are encouraged. Third, although label components were classified using a standard approach, some misclassification could still have occurred, given the numerous styles and wording of claims found on food labels. When doubts arose, researchers discussed them and agreed upon a final classification.

This study has a number of strengths. Firstly, at the time of collection, FLIP 2013 was the largest and most comprehensive branded food and beverage database in Canada, and included products sold nationally as well as private label brands. Secondly, the HCST has been validated for use on Canadian packaged foods [56]. Thirdly, the INFORMAS taxonomy was developed based on the CODEX Alimentarius international food standards; it therefore provides a global approach to classify label components, which has already been used in a number of studies worldwide [50-53,73]. As previously reported, many foods and beverages display regulated and unregulated nutrition and health claims on packages (identified as per Canadian regulations and guidelines) [25]. However, the use of an international standardized label taxonomy highlighted the routine use of health-related ingredient claims (e.g., "made with fruit") to communicate nutrition information, which fall outside Canadian nutrition labelling regulations. In addition, Canada does not require the use of QUID in products carrying those claims, unlike many countries in Europe [74,75] and in Australia [76]. The latter also highlights lack of transparency to consumers regarding the contribution of certain ingredients in packaged foods. Moreover, other Canadian studies have evaluated "front-of-pack" symbols (both prevalence and nutritional quality) $[63,77,78]$; however, given that there is currently no government-led "front-of-pack" labelling regulations in Canada, many industry-led "front-of-pack" symbols highlight positive product attributes without emphasizing nutrients of public health concern.

\section{Conclusions}

In conclusion, this study found that packaged foods with nutrition marketing are more likely to align with 2007 CFG's recommendations than foods without nutrition marketing. However, consumers should be aware that nutrition marketing can also be found on foods highly discouraged by dietary guidelines. Using standardized methods to classify different label components can be useful to identify gaps in nutrition regulations (such as the lack of QUID and regulated supplementary nutrition information on Canadian labels) and can be used to compare results with other countries where more extensive policies and regulations have been introduced. This study can provide important 
baseline data to assess outcomes once the new CFG and other nutrition labelling policies in Canada are fully in place.

Supplementary Materials: The following are available online at http:/ /www.mdpi.com/2072-6643/11/2/411/s1, Supplementary Table S1: Examples of health-related claims under the INFORMAS taxonomy Supplementary Table S2: Global Food Monitoring Group food categories.

Author Contributions: Conceptualization, B.F.-A., S.V. and M.R.L.; Data Collection, B.F.-A. and M.A.K.; Formal analysis, B.F.-A.; Supervision, M.R.L.; Application of HCST to FLIP 2013, B.F.-A., M.-È.L., J.T.B. and C.M.; Validation, B.F.-A., M.A.K., M.-E.L., J.T.B. and C.M., Writing-original draft, B.F.-A.; Writing-review \& editing, B.F.-A., M.A.K., S.V., M.-È.L., J.T.B., C.M. and M.R.L.

Funding: This work was supported by research grants from the Canadian Institutes of Health Research (CIHR) Strategic Operating Grant (201103SOK-118150) (M.R.L.); the Earle W. McHenry Research Chair unrestricted research grant from the University of Toronto (M.R.L.); the CIHR Frederick Banting and Charles Best Canada Graduate Doctoral Scholarship (GSD-152299) (B.F.-A.); the Department of Nutritional Sciences Graduate Student Fellowship (B.F.-A.); the CIHR Post-Doctoral Fellowship (MFE-140953) (M.-E.L.); the CIHR Strategic Training Grant in Population Intervention for Chronic Disease Prevention (TGF-53893) (J.T.B); the CIHR Collaborative Training Program in Public Health Policy (J.T.B); the Ontario Graduate Scholarship (J.T.B); the Ontario Graduate Scholarship Indigenous Scholar Award (C.M.); and the CIHR Frederick Banting and Charles Best Canada Graduate Master Scholarship (C.M.). The funders had no role in the design, analysis or writing of this article.

Acknowledgments: The authors thank several members of the L'Abbé laboratory at the University of Toronto (Alyssa Schermel, Theresa Poon, Mavra Ahmed and Kacie M. Dickinson) for their assistance with different components of FLIP 2013 data collection and the calculations of the HSCT scores in FLIP 2013.

Conflicts of Interest: Beatriz Franco-Arellano declares that prior coming to the University of Toronto, she was a PepsiCo Mexico employee. The company had no connection not funding in any way with regard to the present research. Min Ah Kim has no conflict of interest. Stefanie Vandevijvere has received a research fellowship from the New Zealand Heart Foundation during (2015-2017). Jodi T. Bernstein has no conflict of interest. Marie-Ėve Labonté has no conflict of interest. C.M. completed a Mitacs graduate student internship at Nestlé Canada. The company was not involved in any way with regard to the present research. Mary L'Abbé has received research grants from the Canadian Institutes of Health Research, Canadian Stroke Network, Burroughs Welcome Fund, Heart and Stroke Foundation of Canada, International Development Research Centre, University of Toronto, McHenry Chair (unrestricted research funds).

\section{References}

1. World Health Organization. Global Action Plan for the Prevention and Control of Noncommunicable Diseases 2013-2020. Available online: http:/ / apps.who.int/iris/bitstream/10665/94384/1/9789241506236_ eng.pdf?ua=1 (accessed on 10 December 2018).

2. Nikolic, I.A.; Stanciole, A.E.; Zaydman, M. Chronic Emergency: Why NCDS Matter; The International Bank for Reconstruction and Development/The World Bank: Washington, DC, USA, 2011.

3. Anand, S.S.; Hawkes, C.; de Souza, R.J.; Mente, A.; Dehghan, M.; Nugent, R.; Zulyniak, M.A.; Weis, T.; Bernstein, A.M.; Krauss, R.M.; et al. Food consumption and its impact on cardiovascular disease: Importance of solutions focused on the globalized food system: A report from the workshop convened by the world heart federation. J. Am. Coll. Cardiol. 2015, 66, 1590-1614. [CrossRef] [PubMed]

4. World Health Organization. Fact Sheet: Healthy Diet. Available online: https://www.who.int/news-room/ fact-sheets/detail/healthy-diet (accessed on 10 December 2018).

5. Food and Agriculture Organization of the United Nations. Food-Based Dietary Guidelines. Available online: http:/ / www.fao.org/nutrition/nutrition-education/food-dietary-guidelines (accessed on 10 December 2018).

6. Bechthold, A.; Boeing, H.; Tetens, I.; Schwingshackl, L.; Nöthlings, U. Perspective: Food-based dietary guidelines in Europe-scientific concepts, current status, and perspectives. Adv. Nutr. 2018, 9, 544-560. [CrossRef] [PubMed]

7. Montagnese, C.; Santarpia, L.; Iavarone, F.; Strangio, F.; Caldara, A.R.; Silvestri, E.; Contaldo, F.; Pasanisi, F. North and south American countries food-based dietary guidelines: A comparison. Nutrition 2017, 42, 51-63. [CrossRef] [PubMed]

8. Jessri, M.; Lou, W.Y.; L'Abbé, M.R. The 2015 dietary guidelines for americans is associated with a more nutrient-dense diet and a lower risk of obesity. Am. J. Clin. Nutr. 2016, 104, 1378-1392. [CrossRef] [PubMed] 
9. Jessri, M.; Ng, A.P.; L'Abbé, M.R. Adapting the healthy eating index 2010 for the canadian population: Evidence from the Canadian national nutrition survey. Nutrients 2017, 9, 910. [CrossRef] [PubMed]

10. Assmann, K.E.; Andreeva, V.A.; Camilleri, G.M.; Verger, E.O.; Jeandel, C.; Hercberg, S.; Galan, P.; Kesse-Guyot, E. Dietary scores at midlife and healthy ageing in a French prospective cohort. Br. J. Nutr. 2016, 116, 666-676. [CrossRef]

11. Gopinath, B.; Russell, J.; Kifley, A.; Flood, V.M.; Mitchell, P. Adherence to dietary guidelines and successful aging over 10 years. J. Gerontol. A Biol. Sci. Med. Sci. 2016, 71, 349-355. [CrossRef]

12. Voortman, T.; Kiefte-de Jong, J.C.; Ikram, M.A.; Stricker, B.H.; van Rooij, F.J.A.; Lahousse, L.; Tiemeier, H.; Brusselle, G.G.; Franco, O.H.; Schoufour, J.D. Adherence to the 2015 Dutch dietary guidelines and risk of non-communicable diseases and mortality in the Rotterdam study. Eur. J. Epidemiol. 2017, 32, 993-1005. [CrossRef]

13. Hendrie, G.A.; Golley, R.K.; Noakes, M. Compliance with dietary guidelines varies by weight status: A cross-sectional study of Australian adults. Nutrients 2018, 10, 197. [CrossRef]

14. Jessri, M.; L'Abbe, M.R. The time for an updated Canadian food guide has arrived. Appl. Physiol. Nutr. Metab. 2015, 40, 854-857. [CrossRef]

15. Jessri, M.; Nishi, S.K.; L'Abbé, M.R. Assessing the nutritional quality of diets of canadian adults using the 2014 health Canada surveillance tool tier system. Nutrients 2015, 7, 10447-10468. [CrossRef] [PubMed]

16. Health Canada. Canada's Food Guide Consultation-Phase 1 What We Heard Report. Available online: https:/ / www.canada.ca/en/health-canada/services/publications/food-nutrition/canada-foodguide-phase1-what-we-heard.html (accessed on 10 December 2018).

17. Health Canada. Canada's Food Guide Consultation-Phase 2 What We Heard Report. Available online: https:/ / www.canada.ca/en/services/health/publications/food-nutrition/canada-food-guidephase2-what-we-heard.html (accessed on 10 December 2018).

18. Health Canada. 2019 Canada's Food Guide. Available online: https://food-guide.canada.ca/en/ (accessed on 24 January 2019).

19. Swinburn, B.; Vandevijvere, S.; Kraak, V.; Sacks, G.; Snowdon, W.; Hawkes, C.; Barquera, S.; Friel, S.; Kelly, B.; Kumanyika, S.; et al. Monitoring and benchmarking government policies and actions to improve the healthiness of food environments: A proposed government healthy food environment policy index. Obes. Rev. 2013, 14 (Suppl. 1), 24-37. [CrossRef] [PubMed]

20. Swinburn, B.; Sacks, G.; Vandevijvere, S.; Kumanyika, S.; Lobstein, T.; Neal, B.; Barquera, S.; Friel, S.; Hawkes, C.; Kelly, B.; et al. Informas (international network for food and obesity/non-communicable diseases research, monitoring and action support): Overview and key principles. Obes. Rev. 2013, 14 (Suppl. 1), 1-12. [CrossRef] [PubMed]

21. Swinburn, B.; Sacks, G.; Ravussin, E. Increased food energy supply is more than sufficient to explain the US epidemic of obesity. Am. J. Clin. Nutr. 2009, 90, 1453-1456. [CrossRef] [PubMed]

22. Monteiro, C.A.; Moubarac, J.C.; Cannon, G.; Ng, S.W.; Popkin, B. Ultra-processed products are becoming dominant in the global food system. Obes. Rev. 2013, 14 (Suppl. 2), 21-28. [CrossRef] [PubMed]

23. Moubarac, J.C.; Martins, A.P.; Claro, R.M.; Levy, R.B.; Cannon, G.; Monteiro, C.A. Consumption of ultra-processed foods and likely impact on human health. Evidence from Canada. Public Health Nutr. 2013, 16, 2240-2248. [CrossRef]

24. Slater, J.J.; Mudryj, A.N. Are we really "eating well with Canada's food guide"? BMC Public Health 2018, 18, 652. [CrossRef]

25. Franco-Arellano, B.; Bernstein, J.T.; Norsen, S.; Schermel, A.; L'Abbé, M.R. Assessing nutrition and other claims on food labels: A repeated cross-sectional analysis of the Canadian food supply. BMC Nutr. 2017, 3, 74. [CrossRef]

26. Christoforou, A.; Dachner, N.; Mendelson, R.; Tarasuk, V. Front-of-package nutrition references are positively associated with food processing. Public Health Nutr. 2018, 21, 58-67. [CrossRef]

27. Pulker, C.E.; Scott, J.A.; Pollard, C.M. Ultra-processed family foods in australia: Nutrition claims, health claims and marketing techniques. Public Health Nutr. 2018, 21, 38-48. [CrossRef]

28. Hieke, S.; Kuljanic, N.; Pravst, I.; Miklavec, K.; Kaur, A.; Brown, K.A.; Egan, B.M.; Pfeifer, K.; Gracia, A.; Rayner, M. Prevalence of nutrition and health-related claims on pre-packaged foods: A five-country study in Europe. Nutrients 2016, 8, 137. [CrossRef] [PubMed] 
29. Pravst, I.; Kušar, A. Consumers' exposure to nutrition and health claims on pre-packed foods: Use of sales weighting for assessing the food supply in Slovenia. Nutrients 2015, 7, 9353-9368. [CrossRef] [PubMed]

30. Kaur, A.; Scarborough, P.; Rayner, M. A systematic review, and meta-analyses, of the impact of health-related claims on dietary choices. Int. J. Behav. Nutr. Phys. Act. 2017, 14, 93. [CrossRef] [PubMed]

31. Talati, Z.; Norman, R.; Kelly, B.; Dixon, H.; Neal, B.; Miller, C.; Pettigrew, S. A randomized trial assessing the effects of health claims on choice of foods in the presence of front-of-pack labels. Am. J. Clin. Nutr. 2018, 108, 1275-1282. [CrossRef]

32. Nishi, S.K.; Jessri, M.; L'Abbé, M. Assessing the dietary habits of Canadians by eating location and occasion: Findings from the Canadian community health survey, cycle 2.2. Nutrients 2018, 10, 682. [CrossRef]

33. Eidner, M.B.; Lund, A.S.; Harboe, B.S.; Clemmensen, I.H. Calories and portion sizes in recipes throughout 100 years: An overlooked factor in the development of overweight and obesity? Scand J. Public Health 2013, 41, 839-845. [CrossRef]

34. Poti, J.M.; Braga, B.; Qin, B. Ultra-processed food intake and obesity: What really matters for health-processing or nutrient content? Curr. Obes. Rep. 2017, 6, 420-431. [CrossRef]

35. Van Kleef, E.; Dagevos, H. The growing role of front-of-pack nutrition profile labeling: A consumer perspective on key issues and controversies. Crit. Rev. Food Sci. Nutr. 2015, 55, 291-303. [CrossRef]

36. O'Flaherty, M.; Bandosz, P.; Critchley, J.; Capewell, S.; Guzman-Castillo, M.; Aspelund, T.; Bennett, K.; Kabir, K.; Björck, L.; Bruthans, J.; et al. Exploring potential mortality reductions in 9 European countries by improving diet and lifestyle: A modelling approach. Int. J. Cardiol. 2016, 207, 286-291. [CrossRef]

37. Scarborough, P.; Matthews, A.; Eyles, H.; Kaur, A.; Hodgkins, C.; Raats, M.M.; Rayner, M. Reds are more important than greens: How UK supermarket shoppers use the different information on a traffic light nutrition label in a choice experiment. Int. J. Behav. Nutr. Phys. Act. 2015, 12, 151. [CrossRef]

38. Pearson-Stuttard, J.; Kypridemos, C.; Collins, B.; Mozaffarian, D.; Huang, Y.; Bandosz, P.; Capewell, S.; Whitsel, L.; Wilde, P.; O'Flaherty, M.; et al. Estimating the health and economic effects of the proposed us food and drug administration voluntary sodium reformulation: Microsimulation cost-effectiveness analysis. PLoS Med. 2018, 15, e1002551. [CrossRef]

39. Emrich, T.E.; Qi, Y.; Lou, W.Y.; L'Abbe, M.R. Traffic-light labels could reduce population intakes of calories, total fat, saturated fat, and sodium. PLoS ONE 2017, 12, e0171188. [CrossRef] [PubMed]

40. Peñalvo, J.L.; Cudhea, F.; Micha, R.; Rehm, C.D.; Afshin, A.; Whitsel, L.; Wilde, P.; Gaziano, T.; Pearson-Stuttard, J.; O'Flaherty, M.; et al. The potential impact of food taxes and subsidies on cardiovascular disease and diabetes burden and disparities in the United States. BMC Med. 2017, 15, 208. [CrossRef]

41. Cobiac, L.J.; Scarborough, P. Translating the who $25 \times 25$ goals into a UK context: The promise modelling study. BMJ Open 2017, 7, e012805. [CrossRef]

42. Rosettie, K.L.; Micha, R.; Cudhea, F.; Peñalvo, J.L.; O’Flaherty, M.; Pearson-Stuttard, J.; Economos, C.D.; Whitsel, L.P.; Mozaffarian, D. Comparative risk assessment of school food environment policies and childhood diets, childhood obesity, and future cardiometabolic mortality in the United States. PLoS ONE 2018, 13, e0200378. [CrossRef] [PubMed]

43. CODEX Alimentarius. Guidelines on Nutrition Labelling (cac/gl 2-1985); Joint FAO/WHO Codex Alimentarius Commission: Rome, Italy, 2015.

44. Rayner, M.; Wood, A.; Lawrence, M.; Mhurchu, C.N.; Albert, J.; Barquera, S.; Friel, S.; Hawkes, C.; Kelly, B.; Kumanyika, S.; et al. Monitoring the health-related labelling of foods and non-alcoholic beverages in retail settings. Obes. Rev. 2013, 14 (Suppl. 1), 70-81. [CrossRef] [PubMed]

45. Te Morenga, L.A.; Howatson, A.J.; Jones, R.M.; Mann, J. Dietary sugars and cardiometabolic risk: Systematic review and meta-analyses of randomized controlled trials of the effects on blood pressure and lipids. Am. J. Clin. Nutr. 2014, 100, 65-79. [CrossRef] [PubMed]

46. Mozaffarian, D.; Katan, M.B.; Ascherio, A.; Stampfer, M.J.; Willett, W.C. Trans fatty acids and cardiovascular disease. N. Engl. J. Med. 2006, 354, 1601-1613. [CrossRef]

47. Jessri, M.; Wolfinger, R.D.; Lou, W.Y.; L'Abbé, M.R. Identification of dietary patterns associated with obesity in a nationally representative survey of canadian adults: Application of a priori, hybrid, and simplified dietary pattern techniques. Am. J. Clin. Nutr. 2017, 105, 669-684. [CrossRef]

48. Rayner, M.; Vandevijvere, S. Informas Protocol: Food Labelling Module. Available online: https:/ / figshare. com/articles/INFORMAS_Protocol_Food_Labelling_Module/5673643 (accessed on 10 December 2018). 
49. Bernstein, J.T.; Schermel, A.; Mills, C.M.; L'Abbe, M.R. Total and free sugar content of canadian prepackaged foods and beverages. Nutrients 2016, 8, 582. [CrossRef]

50. Kaur, A.; Scarborough, P.; Hieke, S.; Kusar, A.; Pravst, I.; Raats, M.; Rayner, M. The nutritional quality of foods carrying health-related claims in Germany, The Netherlands, Spain, Slovenia and the United Kingdom. Eur. J. Clin. Nutr. 2016, 70, 1388-1395. [CrossRef] [PubMed]

51. Al-Ani, H.H.; Devi, A.; Eyles, H.; Swinburn, B.; Vandevijvere, S. Nutrition and health claims on healthy and less-healthy packaged food products in New Zealand. Br. J. Nutr. 2016, 116, 1087-1094. [CrossRef] [PubMed]

52. Kaur, A.; Scarborough, P.; Matthews, A.; Payne, S.; Mizdrak, A.; Rayner, M. How many foods in the UK carry health and nutrition claims, and are they healthier than those that do not? Public Health Nutr. 2016, 19, 988-997. [CrossRef] [PubMed]

53. Pongutta, S.; Chongwatpol, P.; Tantayapirak, P.; Vandevijvere, S. Declaration of nutrition information on and nutritional quality of Thai ready-to-eat packaged food products. Public Health Nutr. 2018, 21, 1409-1417. [CrossRef] [PubMed]

54. Dunford, E.; Webster, J.; Metzler, A.B.; Czernichow, S.; Ni Mhurchu, C.; Wolmarans, P.; Snowdon, W.; L'Abbe, M.; Li, N.; Maulik, P.K.; et al. International collaborative project to compare and monitor the nutritional composition of processed foods. Eur. J. Prev. Cardiol. 2012, 19, 1326-1332. [CrossRef] [PubMed]

55. Health Canada. The Development and Use of a Surveillance Tool: The Classification of Foods in the Canadian Nutrient File According to Eating Well with Canada's Food Guide. Available online: http:/ / publications.gc. ca/collections / collection_2014/sc-hc/H164-158-2-2014-eng.pdf (accessed on 6 December 2018).

56. Poon, T.; Labonté, M.; Mulligan, C.; Ahmed, M.; Dickinson, K.M.; L'Abbé, M.R. Comparison of nutrient profiling models for assessing the nutritional quality of foods: A validation study. Br. J. Nutr. 2018, 120, 567-582. [CrossRef] [PubMed]

57. Mackay, S.; Vandevijvere, S.; Xie, P.; Lee, A.; Swinburn, B. Paying for convenience: Comparing the cost of takeaway meals with their healthier home-cooked counterparts in New Zealand. Public Health Nutr. 2017, 20, 2269-2276. [CrossRef] [PubMed]

58. Goodman, S.; Hammond, D.; Pillo-Blocka, F.; Glanville, T.; Jenkins, R. Use of nutritional information in canada: National trends between 2004 and 2008. J. Nutr. Educ. Behav. 2011, 43, 356-365. [CrossRef]

59. Vanderlee, L.; Goodman, S.; Sae Yang, W.; Hammond, D. Consumer understanding of calorie amounts and serving size: Implications for nutritional labelling. Can. J. Public Health 2012, 103, e327-e331.

60. Wong, C.L.; Mendoza, J.; Henson, S.J.; Qi, Y.; Lou, W.; L'Abbé, M.R. Consumer attitudes and understanding of cholesterol-lowering claims on food: Randomize mock-package experiments with plant sterol and oat fibre claims. Eur. J. Clin. Nutr. 2014, 68, 946-952. [CrossRef]

61. Corby, L. Eating well. CMAJ 2007, 177, 176. [CrossRef] [PubMed]

62. Kondro, W. Proposed canada food guide called "obesogenic". CMAJ 2006, 174, 605-606. [CrossRef] [PubMed]

63. Franco-Arellano, B.; Labonté, M.; Bernstein, J.T.; L'Abbé, M.R. Examining the nutritional quality of canadian packaged foods and beverages with and without nutrition claims. Nutrients 2018, 10, 832. [CrossRef] [PubMed]

64. Bernstein, J.T.; Franco-Arellano, B.; Schermel, A.; Labonté, M.; L'Abbé, M.R. Healthfulness and nutritional composition of canadian prepackaged foods with and without sugar claims. Appl. Physiol. Nutr. Metab. 2017, 42, 1217-1224. [CrossRef] [PubMed]

65. Government of Canada. Regulations Amending Certain Regulations Made under the Food and Drugs Act (Nutrition Symbols, Other Labelling Provisions, Partially Hydrogenated Oils and Vitamin D). Available online: http:/ / www.gazette.gc.ca/rp-pr/p1/2018/2018-02-10/pdf/g1-15206.pdf (accessed on 15 February 2018).

66. Machín, L.; Cabrera, M.; Curutchet, M.R.; Martínez, J.; Giménez, A.; Ares, G. Consumer perception of the healthfulness of ultra-processed products featuring different front-of-pack nutrition labeling schemes. J. Nutr. Educ. Behav. 2017, 49, 330.e1-338.e1. [CrossRef] [PubMed]

67. Talati, Z.; Pettigrew, S.; Neal, B.; Dixon, H.; Hughes, C.; Kelly, B.; Miller, C. Consumers' responses to health claims in the context of other on-pack nutrition information: A systematic review. Nutr. Rev. 2017, 75, 260-273. [CrossRef] [PubMed]

68. Roberto, C.A.; Khandpur, N. Improving the design of nutrition labels to promote healthier food choices and reasonable portion sizes. Int. J. Obes. (Lond.) 2014, 38 (Suppl. 1), S25-S33. [CrossRef] [PubMed] 
69. Arrúa, A.; Machín, L.; Curutchet, M.R.; Martínez, J.; Antúnez, L.; Alcaire, F.; Giménez, A.; Ares, G. Warnings as a directive front-of-pack nutrition labelling scheme: Comparison with the guideline daily amount and traffic-light systems. Public Health Nutr. 2017, 20, 2308-2317. [CrossRef]

70. Ares, G.; Aschemann-Witzel, J.; Curutchet, M.R.; Antúnez, L.; Machín, L.; Vidal, L.; Giménez, A. Product reformulation in the context of nutritional warning labels: Exploration of consumer preferences towards food concepts in three food categories. Food Res. Int. 2018, 107, 669-674. [CrossRef]

71. European Union. Regulation (ec) No 1924/2006 on Nutrition and Health Claims Made on Foods. Available online: http:/ / eur-lex.europa.eu/legal-content/EN/ALL/?uri=CELEX\%3A02006R1924-20121129 (accessed on 10 December 2019).

72. Australia New Zealand Food Standards Code. Standard 1.2.7-Nutrition, Health and Related Claims. Available online: https:/ / www.legislation.gov.au/Details/F2017C01048 (accessed on 11 May 2018).

73. Nieto, C.; Rincon-Gallardo Patiño, S.; Tolentino-Mayo, L.; Carriedo, A.; Barquera, S. Characterization of breakfast cereals available in the mexican market: Sodium and sugar content. Nutrients 2017, 9, 884. [CrossRef]

74. United Kingdom-Food Standards Agency and Department for Environment Food \& Rural Affairs. Food Labelling: Giving Food Information to Consumers. Available online: https://www.gov.uk/guidance/ food-labelling-giving-food-information-to-consumers-give-a-quantitative-ingredients-declaration-quid (accessed on 19 December 2018).

75. European Commision. Commission Notice on the Application of the Principle of Quantitative Ingredients Declaration (Quid). Available online: https://eur-lex.europa.eu/legal-content/EN/TXT/?uri=CELEX: 52017XC1121(01) (accessed on 19 December 2018).

76. Food Standards Australia New Zealand. Ingredient Lists and Percentage Labelling. Available online: http:/ / www.foodstandards.gov.au/consumer/labelling/ingredients/Pages/default.aspx (accessed on 19 December 2018).

77. Emrich, T.E.; Qi, Y.; Cohen, J.E.; Lou, W.Y.; L'Abbe, M.L. Front-of-pack symbols are not a reliable indicator of products with healthier nutrient profiles. Appetite 2015, 84, 148-153. [CrossRef] [PubMed]

78. Emrich, T.E.; Cohen, J.E.; Lou, W.Y.; L'Abbé, M.R. Food products qualifying for and carrying front-of-pack symbols: A cross-sectional study examining a manufacturer led and a non-profit organization led program. BMC Public Health 2013, 13, 846. [CrossRef] [PubMed] 